\title{
Complexity as new normality: What is going on?
}

A response collected at SEFI 2019

In this paper we aim at presenting SEFI Annual Conference 2019 from the thematic point of view. Authors have creatively reacted to the main theme 'Complexity as the new normality' by targeting different areas of education where complexity arises: project work, curricular changes and connection to the job market are just few examples. The importance of soft skills alongside the core engineering background has motivated an intense discussion on the role of teaching in developing students' skills. We identified the most represented topics at SEFI 2019 and we reflected on the importance of less represented topics such as Lifelong learning, Talent management, Sustainability and 4th Industrial Revolution. We based our decision on the relevance of such topics for shaping the future engineering education practices. We hope to spark the readers' interest and motivate to explore the articles in this thematic issue as well as the Proceedings of SEFI 2019 Conference.

Keywords: SEFI conferences, teaching engineering, learning models, lifelong learning

\section{Acknowledgement}

We wish to thank all contributors to SEFI Annual Conference 2019. We apologize to the authors we did not cite, especially if they are involved in the practices we have mentioned in this article. We thank Alessandro Tarchini (MathWorks) for generating the word cloud in Figure 3.

\section{Author Information}

Anikó Kálmán, Budapest University of Technology and Economics

https://orcid.org/0000-0002-0225-7921

https://www.linkedin.com/in/kalman-aniko-dr-93a74515/

Linda Citterio, European Distance and E-learning Network (EDEN) Secretariat https://orcid.org/0000-0001-8930-5887 https://www.linkedin.com/in/linda-citterio-65930460

How to cite this article:

Kálmán, Anikó, Linda Citterio. “Complexity as new normality: What is going on?” Információs Társadalom XX, no. 2 (2020): 19-32.

= https://dx.doi.org/10.22503/inftars.XX.2020.2.2 


\section{Introduction}

\subsection{What is SEFI}

SEFI (European Society for Engineering Education) is a non-profit international organization and the largest network of engineering education professionals in Europe. Established in 1973, SEFI aims at improving engineering education and strengthening the image of the engineering education professionals.

The network comprises academics, teachers, students and engineering experts from institutions, associations and corporate partners.

SEFI organizes a scientific annual conference, activities for the deans of Engineering Education, ad hoc seminars/workshops led by SEFI Special Interest Groups. SEFI society is involved in scientific publications such as the European Journal of Engineering Education and participates in ERASMUS+ and Horizon2020 projects. In addition, SEFI cooperates with partner and sister engineering organizations in Europe as well as worldwide.

Several SEFI sister organizations were indeed represented at SEFI 2019: ASEE (American Society for Engineering Education), IGIP (International Society for Engineering Pedagogy), BEST (Board of European Students of Technology), CSEE (Chinese Society for Engineering Education) and ASIBEI (Asociación Iberoamericana de Instituciones de Enseñanza de la Ingeniería).

The SEFI annual conferences focus on how to teach, educate, motivate and help the engineers of the future to succeed. SEFI is strongly committed to keep up with the ever-changing trends in the society and culture by adapting the targets of the conferences according to the new roles and expectations set up by the universities.

\subsection{SEFI 2019}

At SEFI 2019 there were 393 participants from 41 countries, where Hungary and The Netherlands were the most represented. The conference programme consisted of four keynote lectures, 1 plenary session focused on the relation between industry and academia, 47 paper sessions, 32 workshops, 11 Special Interest Group meetings with plenary pitches and 1 poster session with plenary pitches. The paper, poster and workshop sessions were organized to accommodate a high number of accepted contributions: 128 Concept Papers, 61 Research papers and 32 Workshops. These publications were accepted at the end of a strict evaluation process, based on a double blind peer review process.

While submitting their contribution, authors were asked to characterize it by choosing a maximum of two topics. 
At the 2019 conference, the following topics were suggested:

- Diversity in Engineering Education?

- Fundaments of engineering education: mathematics and physics

- Gender, inclusion and ethics

- How to detect and attract talents with new generations of learning technologies and networks?

- Impacts of demographics in tertiary education

- Integrated learning environments for the digital native learners

- Lifelong learning

- Network Capital (in the production of knowledge and the popularization of science)

- New Complexity quest in engineering sciences

- New notions of interdisciplinarity in engineering education

- Open and online teaching and learning

- Strong demand for democratic involvement in educational processes

- Sustainability reflecting the complexity of modern society

- Talent management

- 4th Industrial Revolution

One of the ideas behind these topics was to show that through the utilization of data derived from simulations and the production of resources for workbased practical learning as well as the integration of the human-machine intelligence model for the purpose of continuous knowledge enhancement, the development of industrial automation and info communication technologies opens up opportunities for lifelong learning. For the improvement of efficiency and access to the most varied new sources, and in order to provide such sustainable services that reflect the complexity of modern societies, high expectations and pressure are posed on education. In our 'fragmented age', the operational environment is characterized by turbulence, interdependence and complexity. For the transforming world of engineering education, more recent challenges increasingly come from the complex sociocultural, economic, structural and political sectors. It is an expectation towards university science and technology to develop excellence, explore and attract talents and collect the inputs of practicing experts, resulting in cooperation surplus. In the meantime, we also witness the specialization of education and the emergence of new skill sets. Our pragmatic and creative education experts are capable of efficiently promoting the diversity profiles of the education of scholars with new insights and intelligence, combining the entrepreneurial mindset with mental agility, mobility, flexibility and curiosity.

László Ábrahám, CEO of National Instruments Debrecen, intervened at SEFI 2019 with a workshop specifically devoted to present successful cases of cooperation between academia and industry. At this session representatives of LEGO, Knorr-Bremse, Continental, Ericsson and Schaeffler were also invit- 
ed to present the outstanding Hungarian industrial practices and promote a panel discussion on how to support higher education innovation in Hungary.

SEFI 2019 Annual Conference has explored a wide range of the current available methods for teaching engineering subjects in our increasingly digitalized world.

Figure 1 shows the topics proposed at SEFI 2019 and how many times authors have chosen them. As the conference motto was 'Varietas delectat', authors were encouraged to submit contributions also pertaining to other topics than the ones suggested. As a result, 'Another topic' was the most frequently chosen topic. 'New notions of Interdisciplinarity', and 'Diversity in Engineering Education?' were also widely picked. The choice of the first topic reflects the understanding that today's engineering problems can only be solved by a multi-disciplinary approach, the second that institutions are focusing on different equally important priorities. 'Lifelong learning' was also a popular topic, reflecting the importance of continuous professional development after studies, hence the necessity to build a culture of lifelong learning during studies.

On the other hand, none of the authors chose the topic 'Network capital' in the sense of social capital. This may be explained in different ways. It is possible that the authors have not found any correlation with their current research. It is also possible that it is somehow given for granted and already present in the discussion, but not explicitly addressed.

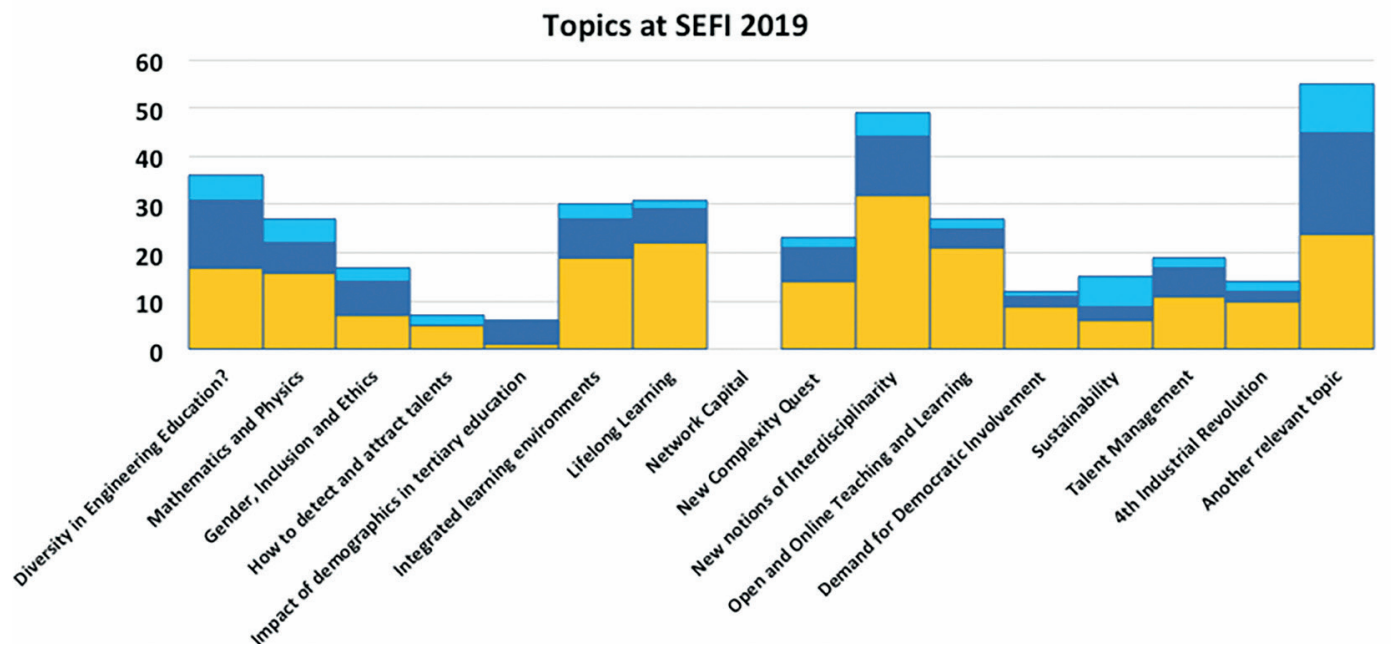

Figure 1. Number of times each topic was picked at SEFI 2019 in concept papers (yellow bars), research papers (dark blue bars) and workshops (light blue bars). Authors could choose maximum two topics per contribution.

All articles - except for the ones presented as posters - were grouped according to their topic into sessions of 60 or $100 \mathrm{~min}$ each. Workshops (100 min each) were not classified into topics in the conference programme and were running in parallel to the paper sessions. 
Figure 2 shows how many sessions we offered in the different topics. 'Mixed topics', 'Interdisciplinarity' and 'Diversity' sessions were the most represented topics, in accordance to the topics assigned by the authors to their contribution. Note that Figure 1 reflects the topics assigned to all contributions, while Figure 2 does not include workshops and papers presented as posters.

\section{Sessions at SEFI 2019}

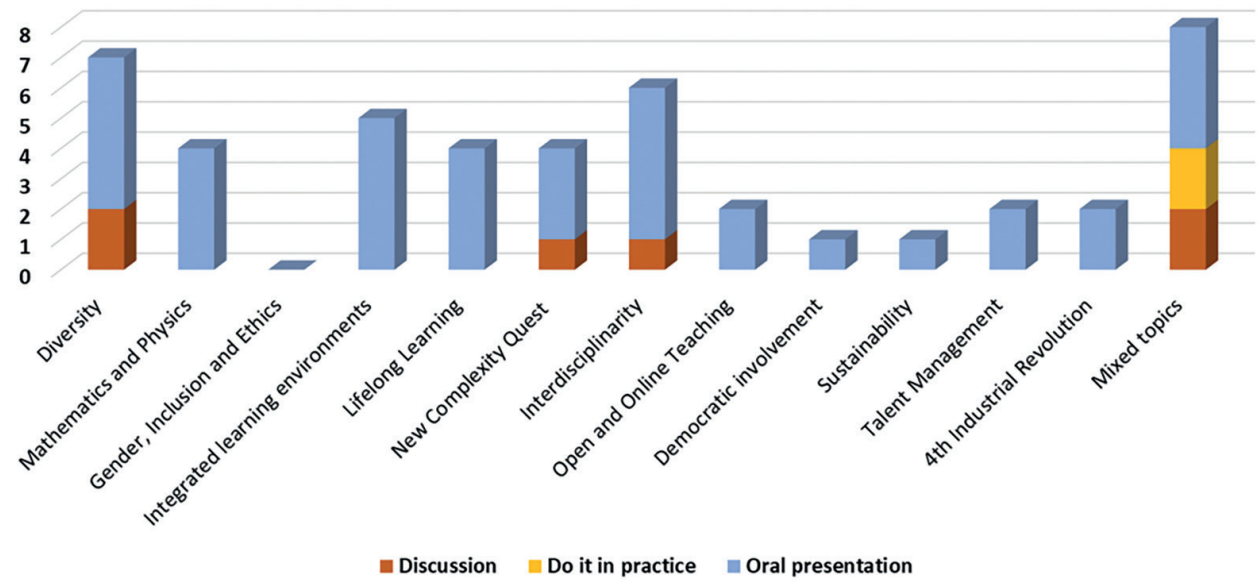

Figure 2. Number of sessions at SEFI 2019 per topic. In each session papers were presented in one of the following formats: discussion, do-it-in-practice, oral presentation.

We recognize that each paper touches upon a larger number of topics and we miss from the analysis a deeper classification of all papers that fell into the categories 'Another topic' or 'Interdisciplinarity'.

In order to infer which are highly discussed topics we chose to address directly the full text of the SEFI 2019 Conference Proceedings. We present the most mentioned terms in the text based on a word cloud analysis (Figure 3 ). The cloud shows that the authors' interests revolved primarily on engineering skills, curriculum/course design, project-based (group) work and learning process and methods, which is expected from a conference in engineering pedagogy.

Based on these initials considerations we reflect upon what is the State of the Art in Engineering Education and what is needed to achieve in the next 10 years in Engineering Education. Graham's report (2018) contains a comprehensive overview of both challenges and constraints of the sector, along with selected case studies from the top-rated engineering programmes. Important barriers identified by the study were the difficulty of alignment between government and higher education goals and the little reward attributed to teaching achievements in university career development. These topics were not strongly developed during SEFI 2019. 


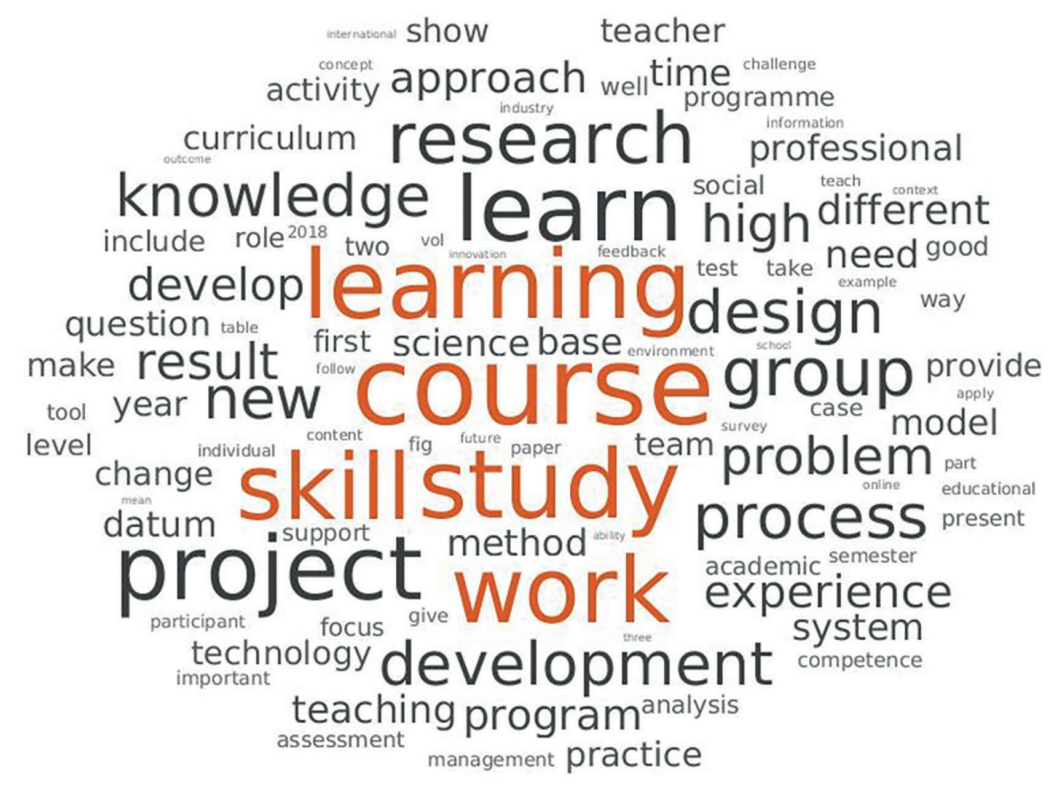

Figure 3. Word cloud containing the most mentioned words in the SEFI 2019 Conference Proceedings after excluding the following words: 'engineering', 'engineer', 'education', 'university', 'student', 'Budapest', 'Hungary', '47th', 'annual', 'conference', '20th', ‘16th', 'September', '2019’.

The Nordic Engineering Hub - as mentioned by Gumaelius and Kolmos (2019) - pointed at sustainability, employability and digitalization as the three major challenges to meet in the years to come. In agreement with these reflections, we selected the following SEFI 2019 topics: Lifelong learning, Talent management, Sustainability reflecting the complexity of the modern society, 4th Industrial Revolution, that are closest to challenges mentioned by $\mathrm{Gu}$ maelius and Kolmos.

The first two selected topics - Lifelong learning and Talent Management - were widely discussed by the contributors to SEFI 2019 (even when not explicitly chosen). Addressing these topics may represent one response to the challenge of employability. Within Talent Management, we identified a subtopic that we call 'Engineering skill set'. Despite the topic itself was not explicit at SEFI 2019, the word 'skills' is dominating the cloud in Figure 3, denoting the intense discussion around competences needed by the future engineers. The findings in Graham's report confirm the importance of employability (measured as time needed for students to find a job after studies) as a key indicator of high performing institutions.

Educators are well aware that a multidisciplinary approach is needed to shape the professional figure of the future engineer, who can deal with multidimensional problems such as sustainable development and the changes brought by the 4th Industrial revolution. This is reflected in the frequent choice of the topic 'Interdisciplinarity'. Despite authors frequently mention 
the necessity of multidisciplinary curricula, we perceive the presence of contradictions and barriers in actually facing them with concrete actions. As shown by Gumaelius and Kolmos (2019) - the educators have reservations concerning changing the curricula in favor of a more generalist approach, where core skills may risk to be learnt more superficially. Another typical barrier is the need for harmonizing theory and practice, in order to support a proficient dialogue between academia and industrial partners.

We then perceive these two topics - Sustainability reflecting the complexity of the modern society, 4th Industrial Revolution - as quite vulnerable, despite their importance. Hence, in the following sections we aim at survey some of the papers presented at SEFI 2019 in order to detect the response of the authors to these crucial themes.

\section{Overview of selected topics}

\subsection{Lifelong learning}

„Without continual growth and progress, such words as improvement, achievement and success have no meaning”. (Benjamin Franklin)

Tun Zaw and Kálmán (2019) collected a number of definitions of lifelong learning present in literature, one of which is: 'the accumulation of skills and qualifications as a means of coping with changes and uncertainty in professional practice'.

Indeed many papers that were classified under the topic 'Lifelong learning' focused on how to build and support a culture of continuous learning, that may enable students to cope with future challenges, for instance employability. Authors have discussed methods of teaching as well as ways of developing students' soft skills.

In addition, authors presented how specific software can support teaching and learning.

Among the discussed methods, PBL (problem- and project- based learning) is an evergreen model. Through PBL, students are able to personalize their learning and memorize deeply for a longer time.

Self-directed learning is an important method, mentioned by a number of authors. By self-managing, self-monitoring and self-reflecting, not only students, but also educators can get a deeper vision of what needs to be done and corrected in their practices and behavior. The method builds on the idea that reflective practices are essential to the lifelong learner. Tun Zaw and Kálmán (2019) present a concise literature review on this topic.

Another frequently mentioned method at SEFI 2019 has been Agile learning. This learning concept is widely used in companies for transferring the 
required competencies to employees. Through this method, skills are learnt directly while dealing with real-life problems, with coaching from more experienced employees.

Several authors at SEFI 2019 (Longmuss and Hoehne; Sten et al.; Velichová and Gabchová) applied and discussed methods based on the principles of Agile learning, customizing it to their own view and experiences. Longmuss and Hoehne (2019) suggest two successful methods to support agile learning: Learning cards and Kanban board. Learning cards are designed by the teachers in order to guide the learning process and save time used to search the literature. The well-known Kanban principles of dividing the work into smaller tasks and visualize them into four groups (To Do, In Progress, Check, Done) is used to sort and keep track of the learning cards, that are then integrated and sorted as tasks. In this way the students' learning path is facilitated and monitored.

Velichová and Gabchová (2019) investigated the level of knowledge acquisition and ability to solve problems of students who were taught Mathematics with eduScrum method. In parallel, Mendonca, Pinto and Nicola (2019) obtained a strong positive feedback from Mathematics students who were taught with this method.

Sten et al. (2019) focused on Scrum - widely used in Agile learning - and proposed a combined approach between Agile Scrum and Lean Kanban (Scrumban). The authors received very positive feedback especially on the formative evaluation in the Scrumban process: students appreciated assessment during the course rather than just at the end.

Formative assessment is typical in online learning where virtual coaches and tutors can also regulate learning and certainly support students' continuous assessment, while relieving some of the teachers' workload.

The use of peer assessment is also quite popular in order to relieve teachers' workload and engage students more. IPAC (Individual Peer Assessed Contribution) by Grammenos at al. (2019) serves as a pedagogical tool to train graduates to give professional feedback to each other within group projects. Seatwo (2019) showed that the use of this tool increased engagement and motivation of students to learn.

All these methods should guide students to become self-motivated individuals, constantly seeking for personal development.

Concerning development of the teachers, the Chinese Academy of Sciences observed that knowledge is updated at high speed and researchers of its network needed a platform for learning the required skills in short time. Zhao et al. (2019) described in detail how the Chinese Academy of Sciences developed a special learning environment - CASmooc - with the purpose of connecting the scientists of the CAS and allowing them to learn new skills, for instance through micro courses.

The content of this platform was built on the basis of other worldwide successful platforms and by surveying the needs of 872 researchers of different title 
level. These researchers identified in particular the following needs: to learn in a short time about interdisciplinary content, to gain knowledge beyond their own field of expertise, and to acquire skills in scientific management and literacy.

Online platforms such as the one created by the CAS are being developed and updated continuously as a response to support and nurture the lifelong learning mentality both in students and educators.

\subsection{Talent management}

At SEFI 2019 the concept of 'talent' has been present in two topics, containing the questions:

\section{- How to attract talent?}

\section{- How to manage talent?}

In today's increasingly growing world, recruiting and nurturing talent is challenging. There are already steps taken to help individuals along their ways from elementary school all the way until the end of university. First, these primary institutions need to find enough dedicated and passionate people for the given science. Second and most importantly, secondary schools, workshops and workplaces need to make sure that whenever students are ready to join them, they feel welcome and are offered up-to-date opportunities.

For maintaining the quality of both recruitment and development, lower ranking universities should highly focus on building a reputation of excellence. Engineering universities are building the right environment for the students by creating professional education system in engineering specialization, extracurricular and networking activities, offering exceptional employability perspectives with access to highly recognized positions. In order to achieve such target, engineering schools shall learn from other highly ranked attractive environments (Moulignier et al. 2019).

Recruiting talent may start at a very young age. In order to foster the interest in STEM studies in future generations, there are several universities in the world that organize the so-called „Children's University Programmes”. These programmes are mostly summer camps, even if sometimes they last for a whole academic year. The objectives are to offer insights and to broaden the kids' interest in scientific fields at a very young age (8-14). Through these camps kids are often advised and guided by actual university students around campus. In addition, the kids need to fulfill some teamwork projects' requirements that help them develop cooperative skills (Dallos et al. 2019).

The quality of higher education has been developing but still it is not developing fast enough to keep track of the scientific advancements in research. This gap requires both the students and the teaching environment to expand the curriculum with workshops, camps, internships and insights into the profes- 
sion, research involvements. These are key assets to become a true professional in the field of studies with quality and up-to-date knowledge. Indeed newly graduated students may get lost when their acquired skills are not in line with those required by the job market. This issue has created discussion and constant attention to study programme building. In the view presented at SEFI 2019, the choice of subjects and field work should both support the role and job but most importantly the skills that students will later on use in their future career.

\subsubsection{Engineering skill set}

Inclusion of soft skills into degree programmes has become increasingly important during the past 20 years all over Europe since employers started putting more emphasis on graduates' soft competencies such as team working, leadership and communication (Pyrhönen et al. 2019).

Hence, some engineering curricula are adapting and hosting multi-disciplinary as well as cross-cultural projects in response to these needs. Even though the importance of such competencies (next to the knowledge of core engineering subjects) has been largely recognized, there are differences in how universities have incorporated them into their curricula and how competencies are valued in degree programmes (Pyrhönen et al. 2020, p. 71). Leandro Cruz et al. (2019) - that was awarded the Best Student Paper at SEFI 2019 - have addressed this topic with a special focus on communication skills. Engineers are prompted to refine their communication skills in order to manage the human resources and handle more successfully the relations with customers and suppliers.

Today's students can learn by themselves a lot easier with all the data available online for them. More individuality is being involved everyday into self-development, just because there is decreasing need to transfer the information from teacher to student. This makes a huge difference in higher education systems as well as in post-studies learning. Nevertheless, students need to be guided through an increased amount of available material and deep research is needed to prove whether the data sources are valid. Critical mind set is therefore an essential skill for future engineers.

Craps et al. (2019) explored congruency between career choices compared to students' competencies and interests. The authors found that circa $20 \%$ of the students do not have a clear self-perception and only half of the students that are aware of their capabilities can align themselves with the job roles. A deeper self-insight and awareness of the professional role are therefore clearly envisioned.

Introducing and practicing entrepreneurial skills is a powerful strategy to train future engineers. The Swiss DTI (Department of Innovative Technologies) Startup Garage created an opportunity for young students to develop, try and take advantage of their entrepreneurial skills (Citraro et al. 2019). The ideas are collected through an innovative App (PingeIApp) that matches students' ideas 
with potential mentors. A dedicated committee evaluates the ideas and chooses the students who will have the opportunity to develop their idea into a Startup. After each academic year, a supervising crew decides whether students can maintain their status as 'Idea Startupper'. The main objective is to create an innovative and ever-developing teacher education and teaching practice. The programme's number one advantage is to help young students to experiment themselves as entrepreneurs without any risk and learn to become one.

\subsection{Sustainability reflecting the complexity of modern society}

We support the idea that achievement of the Sustainable Development Goals requires a complex, multidisciplinary approach, where experts representing different fields are able to collaborate and negotiate.

Zilahy and Zsoka (2019) - that was awarded the Best Concept Paper at SEFI 2019 - believe that the focus of future trends in engineering education should shift from the content of teaching to methodology. The authors presented and advocated the use of three major methods: 1) role plays; 2) social innovation labs; 3) consultation projects with the participation of civil sector organizations.

Role plays are simulations where students can assume fictitious roles and learn to discuss and negotiate solutions to real life problems. The advantage of applying this method is that students are challenged to understand the complexity of issues such as climate change and draw input from different disciplines.

Social innovation labs are learning practices that aim at connecting innovation to the real needs of society and are especially well suited for STEM universities.

Consultation projects are based on interaction between students and civil organizations such as NGOs with the purpose of involving students into real life problems. Such projects are run with the participation of a consultancy agent.

Integration of such practices into engineering curricula definitely enriches the learning process.

The software CES EduPack (Granta Design) presented by Fredriksson and Dwek (2019) and Fredriksson and Fung (2019) represents a unique tool to teach sustainability concepts to students as well as professionals. This package may support Materials Education across Engineering, Design, Science and Sustainable Development. The targeted example at SEFI 2019 has been the issue of plastic waste: as plastic's durability is threatening our planet, it is very important to encourage future material engineers to reduce and later avoid the use of plastic materials and achieve a sustainable product life cycle. Such initiatives certainly increase critical thinking and awareness in product design and development.

Both experts and students can benefit from the above-mentioned practices by getting deeply engaged and more motivated to act. The complexity of our 
society requires more and more people to look at the sustainability goals as their own personal objective to unite as one and behave regarding to that.

\subsection{4th Industrial Revolution}

Sustainability and Industry 4.0 have been dominating debates as the most pressing challenges for society in general and for engineering in particular. Industry 4.0 is a vision on how new technologies will play a key role in the future. As climate change is such an urgent issue, it is expected that the vision of Industry 4.0 includes and addresses sustainable development goals by integrating targeted strategies throughout the entire production and supply chain.

Some research shows that Industry 4.0 will fundamentally change the content and complexity of jobs, because of the different interaction between technological developments, especially in automation, optics, and big data.

Peters et al. (2019) - that was awarded the Best Research Paper at SEFI 2019 - investigated how Industry 4.0 is affecting academia and which competencies CEOs and HR directors are actually looking for. As addressed by the authors, it is crucial to nurture the dialogue with industries and understand which competencies are required. Engineering education shall adopt the new concepts and prepare students to acquire such competencies.

According to employers, future tech workers need 1) a good understanding of the business and business processes, 2) the motivation to develop themselves continuously in order to stay up to speed with new technologies, 3) the ability to collaborate with tech workers of other disciplines.

Adjusting to the newest technologies and cooperating with the opportunities Industry 4.0 is offering people can highly affect efficiency and will lead, in the long term, into knowledge diversification. The progress in industrial automation and ICT opens new possibilities for lifelong learning, utilizing data from simulations, work-based practical learning and integration of human-machine intelligence models for continuous knowledge enhancement.

Education must be visionary to reach efficiency gains, new sources and to offer sustainable services that reflect the complexity of modern societies.

The societal implications of topics such as Industry 4.0 and Sustainability are huge and indeed the public opinion is often pointing at engineers as the problem-solvers. Therefore we expect that popularity and relevance of these topics increase also in Engineering Education.

\section{Conclusion}

Once again SEFI has provided an up-to-date networking forum for international engineering experts. Furthermore, SEFI has been succeeding in acting as a bridge over the gap being created between students and professionals. 
The variety of topics at SEFI conferences shows the wideness of the current interest and the diversified engagement in the field of engineering education.

The increasing instability of the working environment requires engineering education to continue creating and strengthening students' skills for dealing with long-term uncertainties.

In parallel, there is need for acknowledging the efforts of teachers by adding value to their profession.

\section{References}

Ábrahám, László Csaba. "Hungarian industry-university showcases.” In: Proceedings of the 2019 SEFI Annual Conference, 2030-2033. Budapest, Hungary.

Citraro, Mauro, Silvano Cometta, Cristina Carcano, Lorenzo Sommaruga, Alan Righetti, and Tatiana Cataldo. "Startup Garage_The way to apply knowledge.” In: Proceedings of the 2019 SEFI Annual Conference, 249-258. Budapest, Hungary.

Craps, Sofie, Maarten Pinxten, Heidi Knipprath, and Greet Langie. "Exploring Congruency between Engineering students' Professional Role Preference, Competences and Career Choice.” In: Proceedings of the 2019 SEFI Annual Conference, 1506-1518. Budapest, Hungary.

Dallos, Gyorgyi, Laszlo Farkas, Gabor Hornyánszky, Marta Láng Lázi, and Monika Lukács. “Children's University at Budapest University of Technology and Economics.” In: Proceedings of the 2019 SEFI Annual Conference, 292-301. Budapest, Hungary.

Fredriksson, Claes and Mauricio Dwek. "A software tool for Lifelong Learning in Engineering Education.” In: Proceedings of the 2019 SEFI Annual Conference, 423-432. Budapest, Hungary.

Fredriksson, Claes and Abbie Fung. "Life-Cycle Engineering and Sustainability in the Classroom: Tackling the Issue of Plastic Waste.” In: Proceedings of the 2019 SEFI Annual Conference, 2049-2050. Budapest, Hungary.

Graham, Ruth. "The global state of the art in engineering education.” Published by Massachusetts Institute of Technology (MIT), 2018. https://jwel.mit.edu/sites/mit-jwel/files/assets/ files/neet global state of eng edu 180330.pdf

Grammenos, Ryan, Pilar Garcia Souto, Isobel Chester and Lucia Albelda Gimena. "Peer assessment of individual contribution in group work: a student perspective.” In: Proceedings of the 2019 SEFI Annual Conference, 1594-1604. Budapest, Hungary.

Gumaelius, Lena Birgitta and Anette Kolmos. "The Future of Engineering Education: Where Are We Heading?” In: Proceedings of the 2019 SEFI Annual Conference, 1663-1672. Budapest, Hungary. 
Leandro Cruz, Mariana, Darren Carthy, and Sofie Craps. "Communication Activity Implementation over 3 Engineering Universities: Values and Challenges.” In: Proceedings of the 2019 SEFI Annual Conference, 689-698. Budapest, Hungary.

Longmuss, Joerg and Benjamin Hoehne. "Agile learning in continuing education. Learning structures and materials for work based learning.” In: Proceedings of the 2019 SEFI Annual Conference, 726-734. Budapest, Hungary.

Mendonca, Jorge, Carla Pinto, and Susana Nicola. "Effectiveness of Active-learning Methodologies in Math Courses for Engineering Students.” In: Proceedings of the 2019 SEFI Annual Conference, 755-769. Budapest, Hungary.

Moulignier, Romain, Maryse Gille, and Klara Kövesi. "Take the way of excellence! What makes French engineering schools so attractive for talented students?” In: Proceedings of the 2019 SEFI Annual Conference, 1773-1782. Budapest, Hungary.

Peters, Sjoerd, Stefan Corporaal, Milan Wolffgramm, and Kristy McGovern. "Preparing technicians for the 4th industrial revolution.” In: Proceedings of the 2019 SEFI Annual Conference, 1835-1850. Budapest, Hungary.

Pyrhönen, Veli-Pekka, Sonja Niiranen, Eila Pajarre. „Engineering Graduates’ Development of Competencies - Views from Academic Stakeholders.” In: Proceedings of the 2019 SEFI Annual Conference, 1851-1859. Budapest, Hungary.

Pyrhönen, Veli-Pekka, Sonja Niiranen, Eila Pajarre. „Newly graduate engineers’ development of expertise and personal competencies .” Információs Társadalom XX, no. 2 (2020): 70-83. https://dx.doi.org/10.22503/inftars.XX.2020.2.5

Seatwo, Alan. "Enhancing group work learning with the Individual Peer Assessed Contribution (IPAC).” In: Proceedings of the 2019 SEFI Annual Conference, 998-1009. Budapest, Hungary. Sten, Harri, Ulla-Talvikki Virta, and Tero Ahtee. "Scrumban learning - agile, lean and transparent framework for practical learning.” In: Proceedings of the 2019 SEFI Annual Conference, 1074-1083. Budapest, Hungary.

Tun Zaw, Oo and Anikó Kálmán. "Lifelong Learning in a (self)complex: monitor; reflect; directed learning situation.” In: Proceedings of the 2019 SEFI Annual Conference, 1222-1231. Budapest, Hungary.

Velichová, Daniela and Jana Gabchová. "EduScrum Method in Teaching Mathematics for Engineers.” In: Proceedings of the 2019 SEFI Annual Conference, 1962-1971. Budapest, Hungary.

Zhao, Yixia, Yiyuan Tao, Kun Jin, and Runqqiang Wang. "Practical Research on the Lifelong Learning Model of the Largest Scientific Research Institution in China.” In: Proceedings of the 2019 SEFI Annual Conference, 1319-1328. Budapest, Hungary.

Zilahy, Gyula and Agnes Zsoka. "Innovative methods of teaching Sustainable Development.” In: Proceedings of the 2019 SEFI Annual Conference, 1329-1341. Budapest, Hungary. 